\title{
Structuralism and Postmodern Discourse
}

\author{
Thomas Hauer \\ University of Žilina
}

\begin{abstract}
The dominant features of the post-war intellectual scene in France were existentialism, phenomenology, and Marxism, as well as efforts to synthesize them. In the 1960s, these theoretical currents had to cope with new perspectives and ideas brought to the world of theory by the linguistically-oriented discourse of Saussure's structuralism and Lacanian psychoanalysis. Structuralists tried to apply structurally-linguistic model to the humanities and designed the new concept of the language, subjectivity, and society. Levi-Strauss applied the structural-linguistic analysis to the study of myths and family relationships; Lacan developed psychoanalysis based on structuralism; Althusser comes with a structuralist interpretation of Marx. Structuralists attempted to analyse the unconscious codes, rules, and binary oppositions that create the meaning, thus organizing social systems, such as sexual behaviour, fashion, culinary arts, myths, etc. Structures are unconscious, because their product and effects always overlap them. Structuralism therefore does not study individual isolated phenomena, but it moves from the analysis of phenomena that are consciously understood or known to participants in the particular discourse to their "unconscious infrastructures." Structuralists always emphasized rigorously scientific status of their theories; at the same time, applying structurally-linguistic concepts on humanities was supposed to help to make them scientific again.
\end{abstract}

Keywords: linguistic structuralism, parole, post-structuralism, postmodern philosophical theory

\section{Introduction: Ferdinand de Saussure and the Initial Premises of His Theories}

Structuralists criticized the concept of the subject that was treated in the philosophical tradition from Descartes to Sartre. In their concept, the subject was radically fragmented, distributed, deconstructed, and dispersed. The identity of the subject is constantly questioned. The traditional concept understands the "subject" as "I" that thinks, speaks, acts, feels, and so on. Therefore, the subject plays a crucial role consisting in the fact that the reality, which someone is trying to explain, comes from "his" judgment and "his" intuition. Deconstruction of the subject ${ }^{1}$ means that explaining the given fact takes place on the basis of conventions, which are beyond the conscious understanding of the researcher. For example, a spokesman of a specific language is not aware of a phonological and grammatical system, from whose point of view his opinions, arguments, and perceptions will be explained. The subject may not necessarily be aware even of his own psychological arrangement or the system of social norms that govern his behaviour.

Deconstruction of the subject thus consists in his decomposition into basic components; what becomes these components are interpersonal systems of conventions. The subject is fragmented and dissolved when "his"

Thomas Hauer, Prof., Department of Philosophy and Religious Studies, Faculty of Humanities, University of Žilina, Slovakia; main research fields: Postmodern Philosophy, Contemporary Philosophy, Philosophy of Technology, Ethics, and Philosophy of the 20th Century. 
functions are attributed to various systems that operate through him. Research in linguistics, psychoanalysis, anthropology, etc., decentralized the subject in relation to the patterns of his desire, language forms, or in relation to the mythical. During the deconstruction ${ }^{2}$ of the subject into a system components that are, however, trans-subjective, the "subject" is increasingly proving to be a social construct, as a result of the system of conventions.

From this point of view, when one speaks cleverly, "he conforms to the language" that speaks through him, just as the society or his desires speak through him. Even an idea of personal identity emerges only through the culture's discourse. "I" is nothing predetermined; it begins to exist at a lower level, which has its origins in childhood as what others see and what they define. Thus, structuralism transforms the former aspect, which makes the society the outcome of an individual's behaviour and insists that human behaviour is made possible by collective social systems acquired by an individual consciously or unconsciously. Some representatives of structuralism, such as Michel Serres, use expressions like—structure, structural—and accept the definition of the structure as it was defined by the mathematician Nicolas Bourbaki ${ }^{3}$ (it is a collective pseudonym of a group of French mathematicians from 1939). Others, such as Levi-Strauss, prefer the Saussurean term-system. Despite the fact that these authors work in different study areas and they belong to different generations, they all find analogous problems, methods, and solutions. Linguistics in the interpretation of Ferdinand de Saussure is justifiably regarded as the starting point of structuralism. Therefore, let us take a closer look at Saussure's theory of language.

Saussure was not satisfied with the state of linguistics; in his opinion, it "never sought to determine the nature of the subjects that it studied, and without this basic step, science cannot develop a reasonable method" (Saussure 1959). ${ }^{4}$ Given that human speech is a very complicated and complex phenomenon that includes a wide range of heterogeneous factors, its study can be approached from many, often conflicting points of view. For example, we can study the way in which we utter a particular sound using the mouth, tongue, and vocal cords. Or we can explore the sound wave and the way it acts on the auditory mechanism, or analyse grammatical and semantic rules that we must develop if we are to communicate with other speakers of our native language. The linguist is therefore compelled to ask the question what is the object of his study, or in other words, what is-the language?

Saussure's answer to this question is that the language is a system of signs. Sounds can be considered a language only if it serves to express or communicate signs. Otherwise, it is not a language. To be able to communicate, thoughts must be a part of the system of conventions, the system of signs. The sign is the union of the form that signifies and which Saussure calls signifiant, and the signified idea called signifié, i.e., the signified concept. The signifier and the signified do not exist separately, but only as the components of the sign. Thus, signs are a major factor of the language, therefore we must continue to examine the nature of the sign itself.

The basic quality of the linguistic sign is that it is arbitrary. A particular combination of the signifier and the signified is an entirely arbitrary entity. ${ }^{5}$ What Saussure has in mind under the arbitrary nature of the sign is that there is no natural or necessary connection between the signifier and signified. Given that the relationship between the signifier and the signified is arbitrary, there is no inevitable reason why one idea should be associated with a given signifier rather than with another one. There is also no fundamental property, a kind of nucleus, which the idea would need to have to be considered the proper signified for the signifier. Thus, the language not only allocates arbitrary names to groups of independently existing ideas. It also establishes an 
arbitrary relationship between the signified which it had chosen on the one hand, and the signifiers which it had chosen on the other hand. Each language creates a different set of the signifiers dividing the continuity of sounds differently, and also a different group of signified. Thus, each language has a characteristic, hence arbitrary way of organizing the world into concepts or categories.

It is due to the fact that the sign is arbitrary, i.e., it is the result of the division of the continuum in a manner typical of the language to which it belongs; it cannot be handled as a separate entity, but we always have to view it as a part of the system. Therefore, the identity of the sign is purely a function of differences in the system. Thus, there are only differences in the language. Hence, the most accurate characteristic of the sign is that it is what other signs are not. ${ }^{6}$ Therefore, blue is what is not red, grey, yellow, black, etc. This principle applies to each signifier as well as signified.

The sign in a sense bears the "marks" of all the other signs. What is traditionally considered an "image of reality" is retold by Saussure as the network of differences. To explain the meaning of a word or a sentence means to fill the space with other signs and define the differences that characterize this space. The network of differences is therefore always already in place when we try to define the meaning or its interpretation. Thus, through the prism of Saussure's theory of language, to study man and society is to study different sign systems, which are used by man and his culture to organize the world and give it a meaning. Let us ask ourselves now what is the nature of a linguistic unit and what is its identity? So we have come to the conclusion that both the signifier and the signified must be defined in terms of its relationship to other signifiers and signified. So if we define a unit of language, we must distinguish among those purely relational and abstract units and their physiological realizations. Sounds that we make when we have a conversation are not linguistic units of the system themselves, as well as the colour that we have identified, calling the sky blue, is not the same thing as the linguistic unit "blue." The linguistic unit is therefore a form, defined by relationships separating it from other units.

Applying this procedure, we have reached the decisive Saussurean opposition between langue and parole. La langue is a system of the language, the language as a system of forms, whereas parole is speech that is realized through the language. La langue is therefore a set of forms that an individual acquires when learning the language. It is a social product whose existence allows individuals to apply linguistic abilities. Parole is a performing aspect of the language and includes combinations used by the speaker when he applies the linguistic system code to express his own ideas, as well as the psychophysiological mechanism that allows him to express these combinations. The opposition of langue and parole provides linguists with an important principle. It separates what is social from what is individual and also leads to the emergence of two distinct disciplines studying sound and its linguistic features. Phonetics, which studies sound in speech from physiological point of view, and phonology, which is not interested in physiological manifestations, but in the difference between abstract units of the signifier acting in the linguistic system. The opposition between langue and parole has important implications for other disciplines, because it encloses the difference between the institution, the basic system, which allows different types of behaviour, and actual cases of such behaviour. By separating langue from parole, Saussure gave an adequate object to linguistics.

\section{Structural Analysis}

In its general concept, the structural analysis is based on the assumption that the complex of social phenomena can be determined by studying their mutual communication, in which event the communication 
means any process of mutual exchange of values, which takes place in the society. Let us now characterize the basic assumptions of the structural analysis. ${ }^{7}$

The Signifier has a decisive role in relation to the signified. The language is not by any means a neutral medium of communication and self-expression.

The sense always results from a combination of elements that do not indicate anything by themselves. In the basis of the sense, there is a certain non-sense. What is generally meant by the meaning of the sense is derived from logic (rational meaning of logical statements), that is something like a logical sense or meaning. Let us recall, e.g., Frege's distinction between the terms having the same meaning, but differing in the way of the quintessence of this meaning, therefore they have a different sense. The expressions the Morning Star and the Evening Star both have the same meaning (the planet Venus), but they differ in how they present this planet. The Morning Star is the brightest star in the morning sky, the Evening Star the brightest star in the night sky.

On the contrary, what is traditionally referred to as non-sense by logic, the paradoxical and contradictory world created by authors like Lewis Carroll, Kafka, Joyce, Proust etc., is the perfect and limitless dimension of the meaning or sense for structuralism.

So what is non-sense, unless it is not nonsense or the presence of the absurd? In seeking to characterize non-sense, structuralism is based on the assumption that it is necessary to distinguish the sphere of the symbolic, the real and the imaginary. An example can be linguistic structuralism, which distinguishes the third element - the structural object — outside the realm of the real (the audio part of the word) and the imaginary (images and concepts associated with words). The symbolic structure is unrelated to the perceptible forms or to figures of imagination or intellectual nature. Symbolic structure is thus characterized by the nature of their atomic elements, combinatorics of elements that do not have a form, meaning, content, representation, empirical reality, etc. This positional or local criterion (symbolic elements have neither an external determination nor an inner meaning, but only positional sense) suggests that the sense is always clear from combinatorics of elements that do not indicate anything themselves. The sense is always the result, the effect (visual, linguistic, etc.). The basic characteristic can be considered that within the base of each sense, there is a certain non-sense, from which the sense rises. The non-sense is neither the absurd nor the opposite of the sense here, but what the sense promotes and produces by circulating in the structure. As noted by G. Deleuze, structuralism owes nothing to Camus and it owes a lot to L. Carroll. ${ }^{8}$

Any structure (economic, linguistic, mythological, etc.) has a paradoxical element or object "x," which is the point of convergence of series. The paradoxical element is eminently symbolic, and therefore it is immanent to both series. The fundamental characteristics of this paradoxical element " $x$ " are:

(1) It is always displaced relative to itself;

(2) It has the property not to be where we look for it, but to be where it is not;

(3) It is missing in its own place, therefore it is not something real;

(4) It escapes its own similarity, therefore it is not an image;

(5) It escapes its own identity, therefore it is not a term;

(6) Due to its omnipresence, its incessant moving, it produces a sense in each series/Deleuze 1993: 36-40/.

The subject is subordinate to the law of the signifier. Decoding the message means to the recipient to detect binary options, which were used by the spokesman to construct the particular communication using a code that is available. It is the code, not the sender that decides what is and is not appropriate. If the language is a code, it is the language that speaks whenever the subject produces and delivers its messages. Speech is not a 
gesture that would give the sense of "experience that is still silent" to a verbal expression. Thus, the meaning only appears along with the signifier, or rather, along with the first oppositions, such as "yes, no" or "something, nothing." Therefore, the importance of communication is not identical with the meaning of the communicated experience. It is the meaning that the experience can receive only in the discourse, i.e., in the system of the indicating oppositions. Insistence on the heterogeneity of the language and the experience is another of the principles characteristic of structuralism.

Places in the structural space are primary in relation to things and real creatures that occupy them. The structure is characterized by a space which is, however, without size, sheer spatium formed step by step as combinatorics of places. Therefore, the scientific ambition of structuralism is not quantitative, but topological. In the analysis of the economic structure, Althusser shows that real subjects are not those who occupy the particular place, specific individuals, real people, but places in the topological space that is defined by production relations. This means that industrial relations are characterized as differential relations (the system of mutual differences), which are not formed among real people, but between objects and factors that initially only have a symbolic value (production subject, labour, profit, etc.). Specific people then occupy space in the structure and carry out the role they are assigned by the specific structural space (e.g., the capitalist) and thus they become bearers of structural relations. Therefore, the real actors are not those who occupy the place and perform its functions, but the structure itself. Similarly, when Foucault speaks of determinations such as—death, desire, work or play—he does not consider them a dimension of empirical human existence; he mainly considers them designation for a place in the structural space, making those who engaged its attention mortals, those who yearn, those who work, or players, by their taking over the specific part, determined by combinatorics of places in the structure itself. Structuralism is therefore inextricably linked with the new form of transcendental philosophy, in which places are superior to those who occupy them.

Social relationships and linkages are formed by the discourse. The above-mentioned principles of structuralism suggest a shift towards the replacement of the studied issue with the analysis of the discourse. The result is that the origin of the meaning can be no longer (e.g., like in phenomenology) placed in the subject, in an individual who is convinced that he expresses himself, but rather it is placed in the language itself. It is therefore the structure itself that decides what—can be or sometimes just has to be said—on various occasions and in different situations. Not the subject, a particular individual, but rather the structure is decisive. The individual is nothing. That is the scandalous message of the structural anthropology, its "new humanism," which the public opinion extracted from it. One of the consequences, which further follows from all the above principles of structuralism, is the belief that social relationships and linkages are formed by the discourse. This formulation is undoubtedly the most concise characteristic of Structuralist debates. Structuralism thus shows us $^{9}$ that the power of institutions over an individual has its origin in the domination of a certain mode of speech. The ruling discourse does not impose so much any specific truths (dogmas- the signified), but rather a mode of speech (formula—signifiers) that the spokesman has to use if he wants to talk about his position.

\section{Conclusion}

Postmodern discourse presented by authors like M. Foucault, J. F. Lyotard, J. Derrida, G. Deleuze, et al., contains the common ground resulting from the development of one line of thought, which advanced from the linguistically-oriented discourse of structuralism, over post-structuralism to postmodernism. The thesis that social relationships and linkages are formed by discourse is an essential prerequisite for understanding the way 
in which these authors analyse the society. The semiologic version of structuralism is probably the most widespread explanation of the origin of structuralism, although certainly not the only possible one. Thus, the basic significance of Ferdinand de Saussure lies not only in his contribution to linguistics, but in the fact that he made a model for the humanities from what at first glance appears to be quite an inaccessible and highly specialized discipline. Perceiving linguistics as a model for other humanities means paying attention to the conventional basis of non-linguistic signs. It always means to distinguish langue from parole, try to go beyond the act, object or subject itself to a system of rules and relationships that allow them to make a difference. Through a philosophical analysis, the text examines the nature of F. de Saussure's linguistic structuralism and its connection with the emergence of post-structuralism and the postmodern philosophical theory.

\section{Notes}

1. Culler, J., “On Deconstruction: Theory and Criticism after Structuralism,” Cornell University Press, 2008, 35.

2. Descombes, V., "Modern French Philosophy,” Cambridge University Press, 1980, 79.

3. Descombes, V., “Modern French Philosophy,” Cambridge University Press, 1980, 85.

4. F. de Saussure, "Course in General Linguistics,” Ed. Charles Bally and A. Sechehaye, New York, 1959, 16.

5. F. de Saussure, "Course in General Linguistics," Ed. Charles Bally and A. Sechehaye, New York, 1959, 68.

6. F. de Saussure, "Course in General Linguistics,” Ed. Charles Bally and A. Sechehaye, New York, 1959, 117.

7. Descombes, V., "Modern French Philosophy,” Cambridge University Press, 1980, 93-98.

8. Deleuze, G., “Logic of Sense,” New York: Columbia University Press, 1989, 44.

9. Sanders, C., "The Cambridge Companion to Saussure.” Cambridge University Press, 2004, 145. 